\title{
Assessing the speciation and the biogeochemical processes affecting the mobility of selenium from a geological repository of radioactive wastes to the biosphere
}

\author{
F. Séby ${ }^{1, *}$, M. Potin-Gautier ${ }^{1}$, E. Giffaut ${ }^{2}$ and O.F.X. Donard ${ }^{1}$ \\ ${ }^{1}$ Laboratoire de Chimie Bio-Inorganique et Environnement, EP CNRS 132, Hélioparc, \\ 2, avenue du Président Angot, 64000 Pau, France \\ ${ }^{2}$ Agence Nationale pour la gestion des Déchets RAdioactifs (ANDRA), 1-7, rue Jean Monnet, \\ 92298 Châtenay-Malabry Cedex, France
}

\begin{abstract}
In the scope of the studies carried out on the geological disposal of radioactive wastes, it is essential to assess the migration behaviour of long lived radionuclides as a function of the physicochemical conditions ( $\mathrm{pH}$, redox potential, temperature, pressure, ...), the nature of the host rocks and the chemical composition of the underground waters. In this study, we have considered the case of selenium which is an element of importance because of its long lived under its ${ }^{79} \mathrm{Se}$ isotope.

A review is first performed on the behaviour of selenium from available studies in natural systems in considering particularly the inorganic Se forms. Later on, these results are transposed to the physicochemical conditions occurring in the vicinity of a geological repository. The most stable forms in this context would be $\mathrm{Se}(-\mathrm{II}), \mathrm{Se}(0)$ and $\mathrm{Se}(\mathrm{IV})$. Several parameters can govern the mobility of these Se species such as the $\mathrm{pH}$, the potential of the water and the presence of solid phases containing iron, manganese or aluminium (oxy)hydroxides on which Se(IV) can be sorbed. Selenide and selenite mobility can also be retarded by precipitation reactions. This is particularly true for Se(-II) in presence of iron(II) and sulfides. The hypothetical presence of microorganisms is also considered because of its importance on the fate of the Se species.
\end{abstract}

Key words. Selenium - radioactive wastes - biogeochemical processes.

\section{Introduction}

Nuclear wastes arise as a result of the industrial activities for the provision of nuclear energy [1-3]. One of the solution proposed to manage these hazardous materials is to dispose them in a geological formation [2,4-6]. The concept is based on multiple barriers system which will protect humans and the natural environment from both radioactive and chemically toxic contaminants of the waste. These barriers will be the container, the waste form, the engineered barriers and finally the host rock and the sediments overlying the rock. The main host media considered are granite, salt and clay formations [2,4-6].

The principal mechanism of migration of radionuclides from the repository to the surface environment is by leaching/dissolution and then transport by flowing groundwater $[4,6,7]$. The return of radionuclides to the biosphere from the repository is then strongly affected by the hydrogeology of the site and by the chemical and geochemical reactions that take place. The release and the transport of the radionuclides may be slowed via ion exchange, sorption and precipitation processes and the following variables are of importance: $\mathrm{pH}$, redox potential, temperature, lithostatic pressure and groundwater composition [6]. Moreover, recent studies have pointed out the effects of microbial activity in the groundwater flow and in underground excavations on the mobility of some nuclides $[6,8]$. It is therefore important to quantitatively and qualitatively predict the reactions that are likely to occur between hazardous waste dissolved or suspended in groundwater and the host rock to estimate the quantities of waste that can be transported in the aqueous phase [9].

Among the different radionuclides of interest, selenium is considered because of the presence in waste of ${ }^{79} \mathrm{Se}$ coming from fission; its half-life value is close to $7 \times 10^{4}$ years $[10,11]$. The chemistry of selenium resembles to that of sulphur because of its proximity to it within group 16 of the periodic table. Selenium, like sulfur, can exist in four different oxidation states: selenide (Se(-II)), elemental selenium $(\mathrm{Se}(0))$, selenite $(\mathrm{Se}(\mathrm{IV}))$ and selenate $(\mathrm{Se}(\mathrm{VI}))$. It can be also present under the form of various organically bound $\mathrm{Se}(-\mathrm{II})$ and these compounds are analogous to those of sulfur and include seleno-amino acids (e.g. selenocysteine and selenomethionine) and methyl selenides (e.g. dimethylselenide, dimethyldiselenide).

The general behaviour of this element being rather complex, it seems essential to identify the predominating equilibria of the different Se species and the influence of parameters such as $\mathrm{pH}$, redox potential, microbial activity and the presence of complexing and precipitating agents on its release during a long period. Therefore, the aim of this paper is to review with the help of the literature the main biogeochemical processes that could affect its migration. In a first time, we have reported the reactions given for natural systems and then, we have tried to transpose them to the conditions occurring in a geological repository of radioactive waste. 


\section{Biogeochemical processes affecting Se mobility}

As most of trace elements, selenium can react with solid mineral phases, can be bound to organic or inorganic ligands, can participate to redox processes or can be transformed by microorganisms. Such microbial action seems low in a geological repository due to the presence of conditions inhibitory to their growth (lack of carbon and other nutrients sources, low water activity and oxygen, and extreme $\mathrm{pH}$ ) [8,12]. However, several microorganisms can survive under these conditions and some studies have shown a microbial activity for depths reaching $500 \mathrm{~m}$, even $2.8 \mathrm{~km}$ and for temperatures as high as $110^{\circ} \mathrm{C}[8,12,13]$.

\section{Se oxidation-reduction reactions}

Oxidation-reduction reactions are important processes that can affect both the chemical speciation and the stability of selenium in natural environment; these reactions are strongly influenced by the potential and $\mathrm{pH}$ parameters. In aqueous medium, a potential-pH diagram as the one reported figure 1 for a Se activity of $10^{-7}$ mol $\mathrm{L}^{-1}$ can provide information on the chemical stability and the redox chemistry of this element as a function of these parameters. The thermodynamic data used to establish this diagram are listed in table I.

At high potential values, $\mathrm{Se}(\mathrm{VI})$ is predominant in a wide $\mathrm{pH}$ range under the $\mathrm{SeO}_{4}^{2-}$ form. In the moderate potential values, $\mathrm{Se}(\mathrm{IV})$ is stable and according to the $\mathrm{pH}$, can be present as $\mathrm{H}_{2} \mathrm{SeO}_{3}, \mathrm{HSeO}_{3}^{-}$or $\mathrm{SeO}_{3}^{2-}$. In reducing environment, elemental selenium can exist in a wide $\mathrm{pH}$ range. Under more reducing conditions, $\mathrm{Se}(-\mathrm{II})$ is predominant with $\mathrm{HSe}^{-}$ as major Se species in solution. However, these observations based on thermodynamic considerations are often misleading when applied to natural waters particularly at trace levels $[14,15]$. An accurate interpretation of the selenium behaviour requires in situ speciation determinations [16-18]. In soils or sediments, several studies evaluated the Se redox changes involved by a simultaneous variation of the potential and $\mathrm{pH}$ parameters by means of speciation techniques. Masscheleyn et al. submitted water suspensions of seleniferous sediments to the following potential-pH combinations: $-200 \mathrm{mV}$ to $450 \mathrm{mV}$ for $6.5<\mathrm{pH}<9$ [19-21]. Under strongly reducing conditions, only the $\mathrm{Se}(0,-\mathrm{II})$ fraction is detectable and represents 80 to $100 \%$ of the total selenium content. Oxidation of this fraction into Se(IV) occurs at $0 \mathrm{mV}$ and, above $200 \mathrm{mV}$, selenites are oxidised in $\mathrm{Se}(\mathrm{VI})$. Under oxidising conditions $(450 \mathrm{mV})$, selenates are the predominant species $(75 \%$ for $\mathrm{pH}$ close to the neutrality and $95 \%$ at $\mathrm{pH}$ ranging from 8.5 to 9 ). These works show that the $\mathrm{Se}(\mathrm{IV})$ oxidation into $\mathrm{Se}(\mathrm{VI})$ is fast at alkaline $\mathrm{pH}$ and slow at acid $\mathrm{pH}$. More recently, Jayaweera et al. obtained similar results from a seleniferous soil during a sequence of oxic-anoxic-oxic transition [22]. The reduction of Se(VI) into $\mathrm{Se}(\mathrm{IV})$ is characterised by a first-order rate constant equivalent to $5.5 \times 10^{-2} \mathrm{~h}^{-1}$. Authors concluded that the reoxidation of the system is a slow process because the $\mathrm{Se}(\mathrm{VI})$ amount at the end of the last transformation does not reach the initial concentration [22]. In these studies, no analytical difference was done between selenide and elemental selenium in the reduced fraction. With the help of different $\mathrm{X}$-ray spectroscopic techniques, other works showed that the predominant reduced Se form is elemental Se [23-25].
Table I. Standard thermodynamic data used to establish the potential-pH diagram.

\begin{tabular}{|c|c|}
\hline Redox reactions & Standard potential (V) \\
\hline \multicolumn{2}{|l|}{$\mathrm{Se}(0) / \mathrm{Se}(-\mathrm{II})$} \\
\hline $\mathrm{Se}(\mathrm{s})+2 \mathrm{H}^{+}+2 \mathrm{e}^{-} \Leftrightarrow \mathrm{H}_{2} \mathrm{Se}(\mathrm{aq})$ & -0.115 \\
\hline $\mathrm{Se}(\mathrm{s})+\mathrm{H}^{+}+2 \mathrm{e}^{-} \Leftrightarrow \mathrm{HSe}^{-}$ & -0.227 \\
\hline $\mathrm{Se}(\mathrm{s})+2 \mathrm{e}^{-} \Leftrightarrow \mathrm{Se}^{2-}$ & -0.641 \\
\hline \multicolumn{2}{|l|}{$\operatorname{Se}(I V) / \operatorname{Se}(0)$} \\
\hline $\mathrm{H}_{2} \mathrm{SeO}_{3}(\mathrm{aq})+4 \mathrm{H}^{+}+4 \mathrm{e}^{-} \Leftrightarrow \mathrm{Se}(\mathrm{s})+3 \mathrm{H}_{2} \mathrm{O}$ & 0.740 \\
\hline $\mathrm{HSeO}_{3}^{-}+5 \mathrm{H}^{+}+4 \mathrm{e}^{-} \Leftrightarrow \mathrm{Se}(\mathrm{s})+3 \mathrm{H}_{2} \mathrm{O}$ & 0.780 \\
\hline $\mathrm{SeO}_{3}^{2-}+6 \mathrm{H}^{+}+4 \mathrm{e}^{-} \Leftrightarrow \mathrm{Se}(\mathrm{s})+3 \mathrm{H}_{2} \mathrm{O}$ & 0.903 \\
\hline \multicolumn{2}{|l|}{$\mathbf{S e}(\mathbf{V I}) / \mathbf{S e}(\mathbf{I V})$} \\
\hline $\mathrm{HSeO}_{4}^{-}+3 \mathrm{H}^{+}+2 \mathrm{e}^{-} \Leftrightarrow \mathrm{H}_{2} \mathrm{SeO}_{3}(\mathrm{aq})+\mathrm{H}_{2} \mathrm{O}$ & 1.090 \\
\hline $\mathrm{HSeO}_{4}^{-}+2 \mathrm{H}^{+}+2 \mathrm{e}^{-} \Leftrightarrow \mathrm{HSeO}_{3}^{-}+\mathrm{H}_{2} \mathrm{O}$ & 1.008 \\
\hline $\mathrm{HSeO}_{4}^{-}+\mathrm{H}^{+}+2 \mathrm{e}^{-} \Leftrightarrow \mathrm{SeO}_{3}^{2-}+\mathrm{H}_{2} \mathrm{O}$ & 0.760 \\
\hline $\mathrm{SeO}_{4}^{2-}+4 \mathrm{H}^{+}+2 \mathrm{e}^{-} \Leftrightarrow \mathrm{H}_{2} \mathrm{SeO}_{3}(\mathrm{aq})+\mathrm{H}_{2} \mathrm{O}$ & 1.139 \\
\hline $\mathrm{SeO}_{4}^{2-}+3 \mathrm{H}^{+}+2 \mathrm{e}^{-} \Leftrightarrow \mathrm{HSeO}_{3}^{-}+\mathrm{H}_{2} \mathrm{O}$ & 1.060 \\
\hline $\mathrm{SeO}_{4}^{2-}+2 \mathrm{H}^{+}+2 \mathrm{e}^{-} \Leftrightarrow \mathrm{SeO}_{3}^{2-}+\mathrm{H}_{2} \mathrm{O}$ & 0.811 \\
\hline Acid-base reactions & $\mathbf{p K}_{\mathrm{a}}$ \\
\hline \multicolumn{2}{|l|}{$\mathrm{Se}(-\mathrm{II})$} \\
\hline $\mathrm{H}_{2} \mathrm{Se}+\mathrm{H}_{2} \mathrm{O} \Leftrightarrow \mathrm{HSe}^{-}+\mathrm{H}_{3} \mathrm{O}^{+}$ & 3.8 \\
\hline $\mathrm{HSe}^{-}+\mathrm{H}_{2} \mathrm{O} \Leftrightarrow \mathrm{Se}^{2-}+\mathrm{H}_{3} \mathrm{O}^{+}$ & 14 \\
\hline \multicolumn{2}{|l|}{$\operatorname{Se}(I V)$} \\
\hline $\mathrm{H}_{2} \mathrm{SeO}_{3}+\mathrm{H}_{2} \mathrm{O} \Leftrightarrow \mathrm{HSeO}_{3}^{-}+\mathrm{H}_{3} \mathrm{O}^{+}$ & 2.68 \\
\hline $\mathrm{HSeO}_{3}^{-}+\mathrm{H}_{2} \mathrm{O} \Leftrightarrow \mathrm{SeO}_{3}^{2-}+\mathrm{H}_{3} \mathrm{O}^{+}$ & 8.4 \\
\hline \multicolumn{2}{|l|}{$\mathrm{Se}(\mathrm{VI})$} \\
\hline $\mathrm{H}_{2} \mathrm{SeO}_{4}+\mathrm{H}_{2} \mathrm{O} \Leftrightarrow \mathrm{HSeO}_{4}^{-}+\mathrm{H}_{3} \mathrm{O}^{+}$ & -2.01 \\
\hline $\mathrm{HSeO}_{4}^{-}+\mathrm{H}_{2} \mathrm{O} \Leftrightarrow \mathrm{SeO}_{4}^{2-}+\mathrm{H}_{3} \mathrm{O}^{+}$ & 1.73 \\
\hline
\end{tabular}

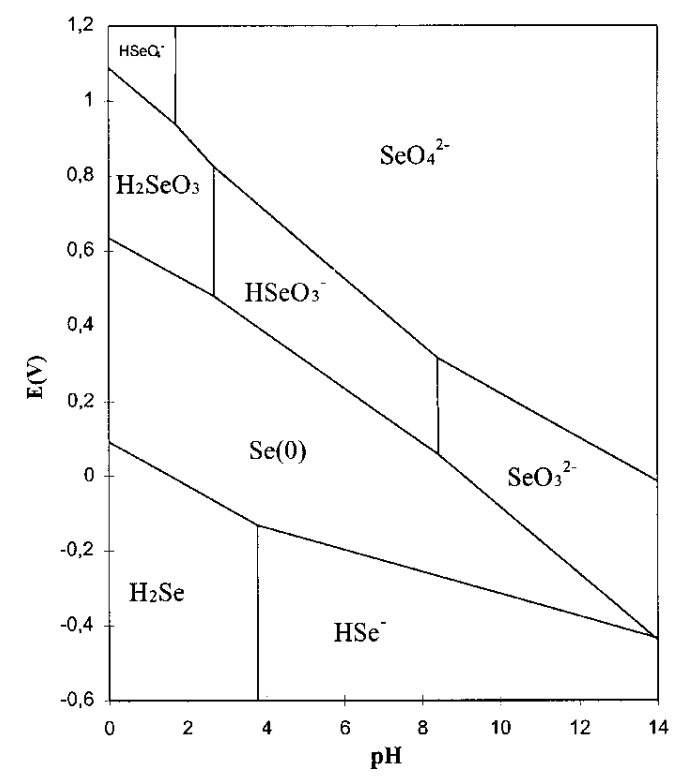

Fig. 1. Se potential-pH diagram at $25{ }^{\circ} \mathrm{C}$ and 1 bar pressure for a dissolved Se activity of $10^{-7} \mathrm{~mol} \mathrm{~L}^{-1}$.

The physicochemical environment of a geological repository of radioactive wastes should impose non-oxidizing 
conditions $[2,4]$. Hence, from thermodynamic considerations, the more stable $\mathrm{Se}$ forms would be $\mathrm{Se}(\mathrm{IV}), \mathrm{Se}(0)$ and $\mathrm{Se}(-\mathrm{II})$ but the presence of $\mathrm{Se}(\mathrm{VI})$ is to be considered because of the low kinetic of its reduction.

Most of the oxidation-reduction reactions discussed before seem very often mediated by the presence of microorganisms [24,26,27]. Microorganisms cannot promote the thermodynamically unfavourable reactions and they act only as kinetic mediators $[8,12]$. In soils or sediments submitted to anaerobic conditions, some bacteria are able to reduce $\mathrm{Se}(\mathrm{VI})$ into red and amorphous elemental Se with $\mathrm{Se}(\mathrm{IV})$ as intermediate species [27-31]. For example, the X-ray examination of Wollinella succinogenes or Bacillus subtilis cultures adapted to grow in the presence of $\mathrm{Se}(\mathrm{VI})$ or $\mathrm{Se}(\mathrm{IV})$ showed the presence of granules in the cytoplasm which consist of elemental selenium [32,33]. It is generally thought that $\mathrm{Se}(\mathrm{VI})$ acts as a terminal electron acceptor to support growth of some organisms. Se(IV) reduction does not follow this mechanism and is more likely to be a detoxification process [34]. The reduction of $\mathrm{Se}(0)$ into $\mathrm{Se}(-\mathrm{II})$ was also reported from Thiobacillus ferroxidans [34] or Micrococcus lactilyticus [29] cultures. For instance, this reaction is not very known but seems conceivable in strongly reducing conditions, the final compound would be volatile hydrogen selenide [29].

The reduced Se fractions have been for a long time considered as unavailable but recent studies showed a reoxidation of these species mediated by microorganisms if the system is in presence of oxygen [26-29,31]. In soils, Zawislanski et al. and Tokunaga et al. have found that 50 to $60 \%$ of the refractory Se can be oxidised into soluble Se in a few days [27,31].

\section{Biomethylation reactions}

Biomethylation of selenium is a well-known process generating volatile compounds from all the natural systems and from all the Se species [35-38]. Biomethylation is more efficient from $\mathrm{Se}$ organic compounds and Se oxidised forms (Se(IV) and $\mathrm{Se}(\mathrm{VI})$ ) [35,38]. This process is based on microbial transformations (aerobic and anaerobic bacteria, fungi, ... $[38,39])$ and the detected gaseous Se species include mainly dimethylselenide (DMSe) and dimethyldiselenide (DMDSe), the first compound being predominant [35,36,38,40]. Addition of carbon sources, alkaline $\mathrm{pH}$ values (8-9) and oxidising to moderately reducing conditions were found to stimulate biomethylation of $\mathrm{Se}[19,20,41]$. From these results, this process seems unlikely in the geological storage conditions because of the low aeration, necessary to the biomethylation of selenium.

\section{Se sorption/desorption reactions}

In oxidised to moderately reduced environment, the selenium distribution between solid and aqueous phases depends mainly on sorption/desorption reactions, particularly at trace levels [42-44]. These reactions can occur on different solid surfaces such as inorganic solids and organic matter [45]. According to the nature of the solid subtract, the immobilisation processes seem different [46-48], they will be treated in two separate parts.

\section{Sorption reactions on mineral surfaces}

On these surfaces, Se adsorption behaviour depends on its oxidation state: selenate sorption is generally much lower than selenite sorption [49-52]. A recent study allowed to show that Se organic compounds such as selenomethionine or selenourea can be also immobilised on iron oxyhydroxide; the mechanism seems however different from that involving inorganic forms [48].

For Se(IV), different studies have shown a strong affinity for materials rich in metallic oxides or/and hydroxides (iron, manganese, aluminium, ...) $[44,47,48,50,52-56]$. The sorption mechanism of this Se form was thoroughly studied and involve very often a ligand exchange reaction $[47,50,51,55-$ 57] with formation of an innersphere surface complex $[42,52,54]$. By means of isotopic exchange experiments on amorphous (hydr)oxide, it was shown both the presence of surface bounding and a partial immobilisation of $\mathrm{HSeO}_{3}^{2-}$ in the deeper layers of the solid [55].

Kinetics of the $\mathrm{Se}(\mathrm{IV})$ adsorption reactions are not yet well understood but the sorbed Se(IV) amounts as a function of time curves show a two steps behaviour: the first part of the curve indicate a fast and linear retention which becomes slower with time $[44,50,53,58]$. On clays, the initial reaction was assigned to adsorption while the second process would correspond to an occlusion [44]. In other works, it was assumed that adsorption rate is controlled by an intraparticular mass transfer in the solid [54,58].

Studies carried out on clays (montmorillonite [44], kaolinite [44], goethite [50,52]), manganese oxide [52,56] or iron oxyhydroxide [48,55] showed that $\mathrm{Se}(\mathrm{IV})$ adsorption is a strongly $\mathrm{pH}$ dependent process. Adsorption is generally maximum in acid medium and decreases with increasing $\mathrm{pH}$. From initial Se(IV) concentrations at trace levels $\left(\mu \mathrm{mol} \mathrm{L} \mathrm{L}^{-1}\right)$, quantitative sorption recoveries were found in the $4-6 \mathrm{pH}$ range for alluvial soils [42], iron oxyhydroxide [48] or manganese dioxide [52]; they are negligible at $\mathrm{pH}$ ranging from 10 to 12 . At low $\mathrm{pH}$, several authors have tried to explain this behaviour by the higher affinity of $\mathrm{HSeO}_{3}^{-}$compared to $\mathrm{SeO}_{3}^{2-}$ with the surface sites and/or by the increase of the positive charges at the surface $[42,44]$.

Several anions can be in competition with Se(IV) sorption and the following sequences were reported. On goethite: phosphate $>$ silicate $\geq$ citrate $>$ molybdate $>$ bicarbonate/carbonate $>$ oxalate $>$ fluoride $>$ sulphate [50], on manganese dioxide: fluoride $>>$ phosphate [47] and on andosols: molybdate $>$ phosphate $>$ citrate $>>$ oxalate $>$ fluoride $>$ sulphate $=$ acetate [52]. According to the solid phase, sequences are different but phosphate and molybdate appears to be the most competing species.

The weaker sorption of $\mathrm{Se}(\mathrm{VI})$ compared to $\mathrm{Se}(\mathrm{IV})$ was observed on different solid surfaces [21,26,44,50] and could be explain by the formation of an outersphere complex at the solid surface [52,59]. Adsorption of $\mathrm{Se}(\mathrm{VI})$ is also strongly affected by the $\mathrm{pH}$ with a similar behaviour to $\mathrm{Se}(\mathrm{IV})[44,49,52,60]$.

The main geological host media considered to store radioactive waste are granite, salt and clay formations $[2,5,6]$. For some clays, such as kaolinite and montmorillonite, the Se sorption behaviour was described previously in this study but additional works seem necessary to assess 
the Se sorption on smectite or illite. On salt, at our knowledge, no work on the retention of selenium has been performed but recent studies are available for granite formations. This rock material can immobilise $\mathrm{Se}(\mathrm{IV})$ and, $\mathrm{Se}(\mathrm{VI})$ in a lesser extent $[10,11,30,61-63]$. These observations were made for both oxidised and reduced conditions $[61,63]$. The selenite adsorption is often quantitative $[11,62]$ and is influenced by the $\mathrm{pH}$ in the same way than described before $[10,11]$. For selenate ions, a sorption recovery close to $40 \%$ was observed $[11,62,63]$. Sorption of these two Se forms are located on the fractures filling material [11,61-63]. The Se(IV) retention occurs mainly on clays and hematite minerals $[10,11,61]$. To explain the sorption of selenate ions on granite, several solid materials were studied such as kaolinite, calcite, pyrite and pyrrhotite. Iron sulfides were found to be the most efficient materials to immobilise $\mathrm{Se}(\mathrm{VI})$ and a Synchrotron-based X-ray absorption spectroscopy examination has demonstrated a partial reduction of $\mathrm{Se}(\mathrm{VI})$ into more reduced Se forms at the mineral surface [63].

\section{Sorption reactions on organic matter}

Interactions between selenium and organic matter such as humic substances were reported for Se(IV) [46-48,64]. From iron oxyhydroxide coated with sodium humate, it was observed a more important immobilisation of Se(IV) compared to the mineral alone [48].

A specific sorption of selenite on the amino groups of some amino acids contained in humic substances was shown [65]. In order to clarify the association between selenite and humic substances, some authors have assigned the retention of $\mathrm{Se}(\mathrm{IV})$ to a microbial reductive incorporation on soils and aquatic systems and this reaction would occur mainly in the low molecular-weight-fraction of the humic substances (fulvic acids) [64]. The mechanism of selenite sorption on organic matter is not yet well understood and incorporation or adsorption reactions could occur alone or in a simultaneous way.

\section{Se precipitation-dissolution reactions}

Selenium can react with inorganic cations to give solid phases that can be responsible of its immobilisation. In soils, equilibrium thermodynamic calculations were carried out to provide a qualitative information on Se solubility from 83 minerals $[66,67]$. The authors concluded that metal-selenate minerals are too soluble to persist in aerated soils. Among the different metal-selenite precipitates, only $\mathrm{MnSeO}_{3}(\mathrm{~s})$ can be formed in strongly acid soils. By means of similar calculations in groundwater at $\mathrm{pH}=7$, it was shown that $\mathrm{Se}$ (IV) and $\mathrm{Se}(\mathrm{VI})$ concentrations are not limited by solubility constraints under oxidised conditions [26]. Conversely, under strongly reduced conditions, metal-selenide minerals were found to limit the Se solubility [66,67]. The most stable minerals are $\mathrm{Cu}_{2} \mathrm{Se}(\mathrm{s})$ in acid soils and $\mathrm{PbSe}(\mathrm{s})$ and $\mathrm{SnSe}(\mathrm{s})$ under neutral to alkaline conditions $[66,67]$. In groundwater with a potential value lower than $0 \mathrm{mV}, \mathrm{FeSe}(\mathrm{s}), \mathrm{ZnSe}(\mathrm{s})$ and $\mathrm{MnSe}(\mathrm{s})$ can exist [26].

From these different works, it seems that the precipitation/dissolution reactions govern selenium solubility only in reduced conditions with formation of solid elemental selenium and metal-selenide [19,21,66-68]. In this environment, it seems that the chemistry of selenium is closely related to those of iron sulfides $[68,69]$. Equilibrium thermodynamic calculations have shown that elemental $\mathrm{Se}, \mathrm{FeSe}(\mathrm{s})$ (achavalite) or $\mathrm{FeSe}_{2}$ (s) (ferroselite) can control Se solubility $[68,69]$. Elemental $\mathrm{Se}$ has a wide stability field under acid conditions and formation of achavalite is favoured for neutral to alkaline conditions. A mixed solid solution phase can also be formed with selenide substituting for sulfide and precipitated FeS will contain FeSe.

In presence of a high selenide concentration and by analogy to the Fe-S system, $\mathrm{FeSe}_{2}$ can coexist with $\mathrm{Se}(0)$ but this last $\mathrm{Se}$ form is thermodynamically favoured. $\mathrm{FeSe}_{2}$ becomes stable only at lower potentials.

\section{Se complexation reactions}

In aqueous phase, selenium can exist under the form of complexes in association with inorganic cations, mainly as ion pairs $[26,66,70]$. A low number of works has experimentally shown the presence of these Se compounds. Only a study on Se speciation in groundwater samples has shown the occurrence of $\mathrm{MgSeO}_{4}(\mathrm{aq})$ by using the specific adsorption properties of the divalent $\mathrm{Se}(\mathrm{IV})$ and $\mathrm{Se}(\mathrm{VI})$ species on $\mathrm{CuO}$ solid particles [70].

Equilibrium thermodynamic calculations for a groundwater at $\mathrm{pH}=7$ containing a total Se concentration of $300 \mu \mathrm{g} \mathrm{L}^{-1}$ have shown that under oxidising conditions $(E>400 \mathrm{mV}), \mathrm{SeO}_{4}^{2-}$ and $\mathrm{CaSeO}_{4}(\mathrm{aq})$ are the predominant species in aqueous solution. For potentials ranging from 0 to $400 \mathrm{mV}$, the most stable species are $\mathrm{CaSeO}_{3}(\mathrm{aq})$ and $\mathrm{SeO}_{3}^{2-}$ and, under more reducing conditions $(E<0 \mathrm{mV})$, only $\mathrm{HSe}^{-}$is present in solution [26]. A similar study was carried out in soil solutions and none of the 27 complexes studied were found to contribute significantly to the total soluble $\mathrm{Se}$ concentration. Only the $\mathrm{SeO}_{4}^{2-}, \mathrm{HSeO}_{3}^{-}, \mathrm{SeO}_{3}^{2-}, \mathrm{H}_{2} \mathrm{Se}$ and $\mathrm{HSe}^{-}$dissolved forms predominate according to the $\mathrm{pH}$ and potential conditions [66].

\section{Conclusion}

This study has allowed to describe qualitatively the predominating processes that can affect the mobility of selenium in natural systems. From these results, we have tried to e valuate the behaviour of this radionuclide in the vicinity of a geological repository of radioactive wastes. In such an environment, the biogeochemical cycle of selenium of the figure 2 summarises the different processes that could be considered.

The Se species of interest would be mainly inorganic and taking into account the low redox potentials occurring in a geological repository, the most stable forms would be $\mathrm{Se}(\mathrm{IV}), \mathrm{Se}(0)$ and $\mathrm{Se}(-\mathrm{II})$. Between these different oxidation states, oxidation/reduction reactions are possible, especially if a microbiological activity exists. However, the kinetics of these reactions are slow leading to the eventual presence of selenate which is very mobile. In moderately reduced environment, $\mathrm{Se}(\mathrm{IV})$ are the predominant Se forms and their mobility is mainly governed by sorption/desorption processes on different solid surfaces such as metallic oxides or hydroxides, clays, granite or organic matter. Water insoluble elemental selenium can exist in a wide $\mathrm{pH}$ range in reducing medium. In strongly reduced conditions, $\mathrm{Se}(-\mathrm{II})$ is the major species and would mainly exist under the form of 


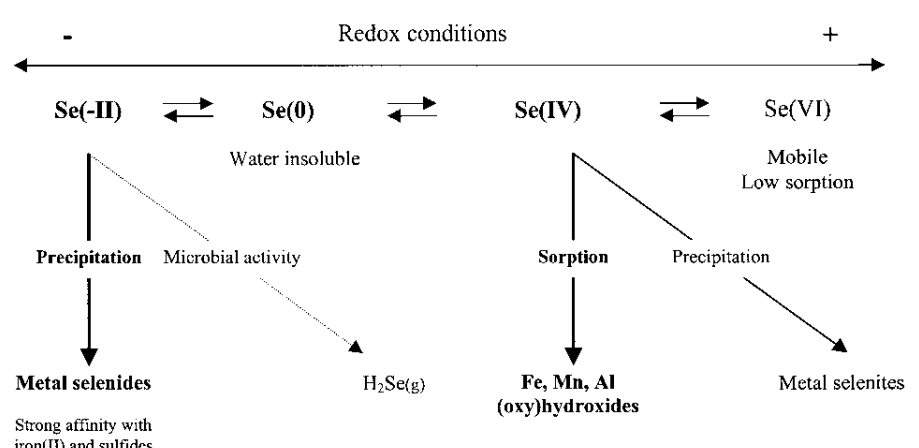

Fig. 2. Biogeochemical cycle of selenium in a geological repository of radioactive waste.

insoluble precipitates in presence of metallic cations. A low number of experimental works has been performed to understand the behaviour of selenium for these conditions but numerous studies stressed the fact that the behaviour of selenide is closely related to those of iron sulfides $[21,68,69]$. A microbial activity could also generate the formation of volatile species such as $\mathrm{H}_{2} \mathrm{Se}(\mathrm{g})$ in reducing conditions. Se biomethylation seems however not favoured because this reaction needs an aerated medium.

Due to the difficulties involved in maintaining the physicochemical conditions of samples from the geological depth to the surface, only studies based on equilibrium thermodynamic calculations are available to describe Se behaviour in the relevant conditions. Such a description can be misleading when applied to natural systems and particularly at trace levels. Indeed, the Se radioactive concentrations in the waste would be close to $10^{-7} \mathrm{~mol} \mathrm{~L}^{-1}$ and could reach $\sim 10^{-10}$ mol L $\mathrm{L}^{-1}$ after dilution when selenium will return to the biosphere. So, it would be interesting to compare results obtained using thermodynamic calculations from Se trace concentrations with a speciation analysis performed in this concentration range to obtain a better interpretation of the behaviour of this element.

\section{References}

1. Guillaumont, R. L'Act. Chim. (R) 1997, 8-9, 4-10.

2. Chapman, N. A. Terra Nova 1994, 6, 5-19.

3. Schapira, J. -P. La Recherche 1997, 301, 65-69.

4. Gascoyne, M. Can. J. Microbiol. 1996, 42, 401-409.

5. De Marsily, G. La Recherche 1997, 301, 70-74.

6. Chopin, G. R.; Wong, P. J. J. Radioanal. Nucl. Chem. 1996, 203, 575-590.

7. Bérest, P. Entropie 1991, 161, 65-73.

8. Gadd, G. M. Endeavour 1996, 20, 150-156.

9. Grenthe, I.; Fuger, J.; Konings, R. J.; Lemire, R. J.; Muller, A. B.; Nguyen-Trung, C.; Wanner, H. Chemical thermodynamics of uranium, (NEA-OECD Ed.), Elsevier, Amsterdam, 1992.

10. Bidoglio, G.; Avogadro, A.; Yllera de Llano, A. Radiochim. Acta 1992, 58/59, 277-280.

11. Gutierrez, M. G.; Bidoglio, G.; Avogadro, A.; Yllera de Llano, A. Radiochim. Acta 1992, 58/59, 277-280.

12. Lovley, D. R.; Chapelle, F. H. Rev. Geophys. 1995, 33, 365381.

13. Fredrickson, J.; Onstott, T. Pour la Science 1996, 230, 90-95.

14. Abdullah, M. I.; Shiyu, Z.; Mosgren, K. Mar. Pollut. Bull. 1995, 31, 116-126.

15. Potin-Gautier, M.; Gilon, N.; Séby, F. J. Eur. Hydr. 1996, 27, 27-44.
16. Séby, F.; Potin-Gautier, M.; Lespes, G.; Astruc. M. Sci. Total Envir. 1997, 207, 81-90.

17. Devereln S. J.; Fio, J. L.; Dubrovsky, N. M. In: Selenium in the environment, Frankenberger, W. T.; Benson, S. Eds., Marcel Dekker INC., New York, 1994; 157-183.

18. Fio, J. L.; Fujii, R. Soil. Sci. Soc. Amer. J. 1990, 54, 363-369.

19. Masscheleyn, P. H.; Delaune, R. D.; Patrick, W. H. Environ. Sci. Technol. 1990, 24, 91-96.

20. Masscheleyn, P. H.; Delaune, R. D.; Patrick, W. H. J. Environ. Qual. 1991, 20, 522-527.

21. Masscheleyn, P. H.; Patrick, W. H. Environ. Toxicol. Chem. 1993, 12, 2235-2243.

22. Jayaweera, G. R.; Biggar, J. W. Soil. Sci. Soc. Amer. J. 1996, 60, 1056-1063.

23. Pickering, I. J.; Brown, G. E.; Tokunaga, T. K. Environ. Sci. Technol. 1995, 29, 2456-2459.

24. Tokunaga, T. K.; Brown, G. E.; Pickering, I. J.; Sutton, S. R.; Bajt, S. Environ. Sci. Technol. 1997, 31, 1419-1425.

25. Zhang, Y.; Moore, J. N. Environ. Sci. Technol. 1996, 30, $2613-$ 2619.

26. White, A. F.; Dubrovsky, N. M. In: Selenium in the environment, Frankenberger, W. T.; Benson, S. Eds. Marcel Dekker INC., New York, 1994; p 185-221.

27. Tokunaga, T. K.; Pickering, I. J.; Brown, G. E. Soil. Sci. Soc. Amer. J. 1996, 60, 781-790.

28. Oremland, R. S.; Hollibaugh, J. T.; Maest, A. S.; Presser, T. S.; Miller, L. G.; Culbertson, C. W. Appl. Environ. Microbiol. 1989, 55, 2333-2343.

29. Oremland, R. S. In: Selenium in the environment, Frankenberger, W. T.; Benson, S. Eds. Marcel Dekker INC., New York, 1994; p 389-419.

30. Ticknor, K. V.; Vandergraaf, T. T.; McMurry, J.; Boisvenue, L.; Wilkin, D. L. Parametric studies of factors affecting Se and Sn sorption, Atomic Energy of Canada Research Company, Canada, Report N ${ }^{\circ}$ TR-723, 1996.

31. Zawislanski, P. T.; Zavarin, M. Soil. Sci. Soc. Amer. J. 1996, 60, 791-800

32. Tomei, F. A.; Barton, L. L.; Lemanski, C. L.; Zocco, T. G. Can. J. Microbiol. 1992, 38, 1328-1333

33. Buchanan, B. B.; Bucher, J. J.; Carlson, D. E; Edelstein, N. M.; Hudson, E. A.; Kaltsoyannis, N.; Leighton, T.; Lukens, W.; Shuh, D. K.; Nitshe, H.; Reich, T.; Roberts, K.; Torretto, P.; Woicik, J.; Yang, W. S.; Yee, A.; Yee, B. C. Inorg. Chem. 1995, 34, 1617-1619.

34. White, C.; Wilkinson, S. C.; Gadd, G. M. Int. Biodeterior. 1995, 35, 17-40.

35. Reamer, D. C.; Zoller, W. H. Science 1980, 208, 500-502.

36. Cooke, T. D.; Bruland, K. W. Environ. Sci. Technol. 1987, 21, 1214-1219.

37. Terry N., Carlson C., Raab T. K., Zayed A. M. J. Environ. Qual. 1992, 21, 341-344.

38. Doran, J. W.; Alexander, M. Soil. Sci. Soc. Amer. J. 1977, 41, 70-73.

39. Karlson, U.; Frankenberger, W. T. Soil. Sci. Soc. Amer. J. 1989, 53, 749-753.

40. Frankenberger, W. T.; Karlson, U. In: Selenium in the environment, Frankenberger, W. T.; Benson, S. Eds., Marcel Dekker INC., New York, 1994; p 369-387.

41. Frankenberger, W. T.; Karlson, U. Soil. Sci. Soc. Am. J. 1989, 53, 1435-1442.

42. Neal, R. H.; Sposito, G.; Holtzclaw, K. M.; Traina, S. J. Soil. Sci. Soc. Amer. J. 1987, 51, 1161-1165

43. Jurinak, J. J.; Tanjii, K. K. J. lrrig. Drain. Eng. 1993, 119 , 848-867.

44. Bar-Yoseph, B.; Meek, D. Soil. Sci. 1987, 144, 11-19. 
45. Öhman, L. O. In: Metal speciation: theory, analysis and application, Lewis INC., Chelsea, 1988; p 1-40.

46. Gustafsson, J. P.; Jacks, G.; Stegmann, B.; Ross, H. B. Agr. Ecosyst. Environ. 1993, 47, 103-115.

47. Saeki, K.; Matsumoto, S. Commun. Soil. Sci. Plant. Anal. 1993, 24, 2375-2387.

48. Tam, S. -C.; Chow, A.; Hadley, D. Sci. Total Envir. 1995, 160, 1-7.

49. Ahlrichs, J. S.; Hossner, L. R. J. Environ. Qual. 1987, 16, 9598.

50. Balistrieri, L. S.; Chao, T. T. Soil. Sci. Soc. Amer. J. 1987, 51, 1145-1151.

51. Alemi, M. H.; Goldhammer, D. A.; Nielsen, D. R. J. Environ. Qual. 1988, 17, 608-613.

52. Saeki, K.; Matsumoto, S.; Tatsukawa, R. Soil. Sci. 1995, 160, 265-272.

53. Del Debbio, J. A. Radiochim. Acta 1991, 52/53, 181-186.

54. Papelis, C.; Brown, G. E.; Parks, G. A.; Leckie, J. O. Langmuir 1995, 11, 2041-2048.

55. Van Der Hoeck, E. E.; Comans, R. N. Environ. Sci. Technol. 1996, 30, 517-523.

56. Parida, K. M.; Gorai, B.; Das, N. N.; J. Colloid. Interface Sci. 1997, 187, 375-380.

57. Barrow, N. J. J. Soil. Sci. 1992, 43, 421-428.

58. Papelis, C.; Roberts, P. V.; Leckie, J. O. Environ. Sci. Technol. 1995, 29, 1099-1108.

59. Davis, J. A.; Leckie, J. O. J. Colloid. Interface Sci. 1980, 74, 32-43.
60. Vuori, E.; Vääriskoski, J.; Hartikainen, H.; Kumpulainen, J.; Aarnio, T.; Niinivaara, K.; Agr. Ecosyst. Environ. 1994, 48, 9198.

61. Ticknor, K. V.; Har ris, D. R.; Vandergraaf, T. T. Sorption/desorption studies of selenium on fracture-filling minerals under aerobic and anaerobic conditions, Atomic Energy of Canada Research Company, Canada, Report No TR-453, 1988.

62. Bidoglio, G.; Cole, T. G.; Soupioni, M.; Garcia Gutierrez, M.; Yllera de Llano,A. J. Radioanal. Nucl. Chem. 1994, 179, 243250.

63. Yllera de Llano, A.; Bidoglio, G.; Avogadro,A.; Gibson, P. N.; Rivas Romero, P. J. Contam. Hydrol. 1996, 21, 129-139.

64. Gustafsson, J. P.; Johnsson, L. Appl. Organometal. Chem. 1994, 8, 141-147.

65. Cohen, R.; Schuhmann, D.; Sinan, F.; Vanel, P. Mar. Chem. 1992, 40, 249-271.

66. Elrashidi, M. A.; Adriano, D. C.; Workman, S. M.; Lindsay, W. L. Soil. Sci. 1987, 144, 141-152.

67. Elrashidi, M. A.; Adriano, D. C.; Lindsay, W. L. In: Selenium in agriculture and the environment, Soil Special Publication N²3, Jacobs, L. W. Ed. Madison, 1989; p 51-63.

68. Masscheleyn, P. H.; Delaune, R. D.; Patrick, W. H. J. Environ. Sci. Health 1991, 26, 555-573.

69. Hatten Howard III, J. Geochim. Cosmochim. Acta 1977, 41, 1665-1678.

70. Reddy, K. J.; Zhang, Z.; Blaylock, M. J.; Vance, G. F. Environ. Sci. Technol. 1995, 29, 1754-1759. 